\title{
Performance of a novel green scale inhibitor
}

\author{
Leila Mahmoodi ${ }^{1}$, M. Reza Malayeri ${ }^{2}$, Farshad Farshchi Tabrizi ${ }^{3}$ \\ ${ }^{1}$ Department of Chemical Engineering, School of Chemical and Petroleum Engineering, Shiraz Uni- \\ versity, Iran \\ ${ }^{2}$ Technische Universität Dresden, Dresden, Germany \\ ${ }^{3}$ Department of Chemical Engineering, School of Chemical and Petroleum Engineering, Shiraz Uni- \\ versity, Iran
}

\begin{abstract}
Many aspects of oilfield scale inhibition with green scale inhibitors (SIs) have remained untouched. For instance, the discharge of large amounts of produced water containing various types of hazardous chemicals, such as SIs into the environment has become a major concern. Instead, environmental regulators encourage operators to look for greener SIs. In this study, the performance of a green SI was investigated using PHREEQC simulation. For a specific case study, two brines are considered to mix incompatibly to estimate the critical mixing ratio that has the highest tendency to scaling. Subsequently, for 50/50 mixing ratio as the critical value, theoptimal dosage of SI and its performance in the presence of two different rocks were investigated such that $450 \mathrm{mg} / \mathrm{L}$ SI would be considered as optimal value. Moreover, the simulated results show that more SI adsorption on calcite would be predicted, compared to dolomite.
\end{abstract}

\section{Introduction}

In the oil and gas industry, one of the primary production problems is mineral deposition resulting from the water-flooding, incompatible water mixing, and/or hydro-fracturing processes that are applied to maintain sustainable hydrocarbon production in oil, gas, or gas-condensate fields [1]. Scaling is the deposition of inorganic salts due to supersaturated conditions when their solubility limit is exceeded. It can cause immediate and severe technical problems such as the reduction in production capacity, reservoir choking, accelerated corrosion and flow loss, or blockage on flow lines and equipment [2], which can influence both production and economic aspects of the process. Generally, the associated expenses due to scaling were estimated at some billion dollars per year in major developed industrialized countries [3].

Therefore, effective scale management is of great practical importance for oilfield development planning which will dominate production viability [4]. The utilization of scale inhibitors (SI) in oilfields is widespread due to their impact on the mitigation of scale formation as an efficient solution to enhance oil recovery (EOR) and prevent formation damage.

In general, the oil industry, like other industries, suffers from the environmental consequences of using hazardous chemicals to inhibit scale formation. The selection of environmentally friendly inhibitors which should be non-toxic, biodegradable, and show no bioaccumulation [1], and their appropriate dosage are two crucial factors to get the optimum 
inhibitory action which must be achieved by simulating the well [5]. Although both types of phosphonate and polymeric SIs have been investigated experimentally [6-10], nevertheless, well-known polymeric environmentally friendly scale inhibitors, like poly aspartic acid (PASP) [11-14], polyepoxysuccenic acid (PESA) [15-17], and carboxymethyl inulin (CMI) [18-21], are gaining increased attention. Moreover, natural organic molecules and plant extracts like the green SIs [13,22-24] in this study,wereassessed as brand-new SIs.

It is evident from the above that the applied study of green scale inhibitor would help to keep the environment safe and mitigate the scaling phenomenon in porous media in the oil industry. Accordingly, the present work endeavors to investigate a green SI for an Iranian oilfield water-flooding process through simulation by PHREEQC to evaluate its performance.Although data on complex interactions between SIs and brines are still lacking, this study nevertheless examines the impact of the presence ofa green SI in an incompatible water mixing process in the absence and presence of rocks using PHREEQC based on their $\mathrm{pH}$ dependency. In other words, this work presents a brand-new approach to a novel green scale inhibitor performance through PHREEQC simulation.

\section{Modeling}

As a major operational problem, i.e., scale formation, which is recognized as a significant cause of formation damage [25], has frequently been observed in various oil reservoirs and interconnected production equipment in Iranian oilfields, specifically near the wellbores. Employment of an efficient green SI would be a perfect solution to overcome formation damage of various types, as well as to safeguard the environment in the water-flooding process.

Scale potential and specific SI performance for a particular case study (Table 1) have been investigated using PHREEQC simulation, as a pH-redox equilibrium geochemical model [26] to estimate the saturation ratio of the minerals that may precipitate, as well as the mass of deposits. Two brines are ionically characterized for expected simultaneous reactions (1-3), which will be taking place as they mix to reach equilibrium [27].

$$
\begin{aligned}
& \mathrm{Ca}^{2+}+2 \mathrm{HCO}_{3}^{-} \rightarrow \mathrm{CaCO}_{3} \downarrow+\mathrm{CO}_{2}+\mathrm{H}_{2} \mathrm{O} \\
& \mathrm{Mg}^{2+}+\mathrm{Ca}^{2+}+\mathrm{CO}_{3}^{2-} \rightarrow \mathrm{MgCa}\left(\mathrm{CO}_{3}\right)_{2} \downarrow \\
& \mathrm{Ca}^{2+}+\mathrm{SO}_{4}^{2-} \rightarrow \mathrm{CaSO}_{4} \downarrow
\end{aligned}
$$

Firstly, the critical mixing ratio of the two brines is examined to find out the maximum amount of precipitated particles at $90^{\circ} \mathrm{C}$ and atmospheric pressure $[21,28,29]$ necessary to simulate incompatible mixing process athigh-temperature standard static tests. Secondly, the critical mixing ratio test is conducted to assess the various dosage of the SI to evaluate the optimum dosage of the SI. Finally, the impact of 10 grams [29] of dolomite and calcite rock's presence is studied to determine the SI adsorption capacity for each rock.

Table 1. Ionic composition of investigated brines

\begin{tabular}{ccc}
\hline Brine & Formation Water & Seawater \\
\hline Ion $(\mathrm{ppm})$ & 2274 & 183 \\
{$\left[\mathrm{HCO}^{-}\right]$} & 665 & 2880 \\
{$\left[\mathrm{SO}_{4}^{2-}\right]$} & 137114 & 26625 \\
{$\left[\mathrm{Cl}^{-}\right]$} & 14840 & 750 \\
{$\left[\mathrm{Ca}^{2+}\right]$} & 3086 & 1350 \\
{$\left[\mathrm{Mg}^{2+}\right]$} & 67102 & 19550 \\
{$\left[\mathrm{Na}^{+}\right]$} & - & 410 \\
{$\left[\mathrm{~K}^{+}\right]$} & 6 & 7.5 \\
$\mathrm{pH}$ & & \\
\hline
\end{tabular}


The aforementioned simulation steps were performed with the help of PHREEQC which handles geochemical reactions at the equilibrium state. After the definition of both formation water and seawater in terms of ionic composition, temperature, pressure, and $\mathrm{pH}$, and mixing these two brines, the equilibrium state of the mixing process was considered. Subsequently, the resultswere obtainedthe mole and mass variations of each participant. It should be noted that the simulations used experimental $\mathrm{pH}$ values after adding different doses of the green SI to seawater.In other words, based on the $\mathrm{pH}$-dependent nature of the simulation software, it is intended to manipulate the $\mathrm{pH}$ values of the SI-added- seawater to study the SI performance in anincompatible mixing process.

\section{Results and discussion}

\subsection{Scale Potential}

To study mineral scale formation at high temperatures which simulates reservoir conditions, incompatible mixing of two brines was performed to estimate the potential of scale formation versus different mixing ratios of the brines. Figure 1 demonstrates that the highest scaling tendency occurs around $50 \%$ formation water which will be considered as the critical mixing ratio due to the maximum amount of predicted precipitates (gr) per one liter of water produced after mixing.

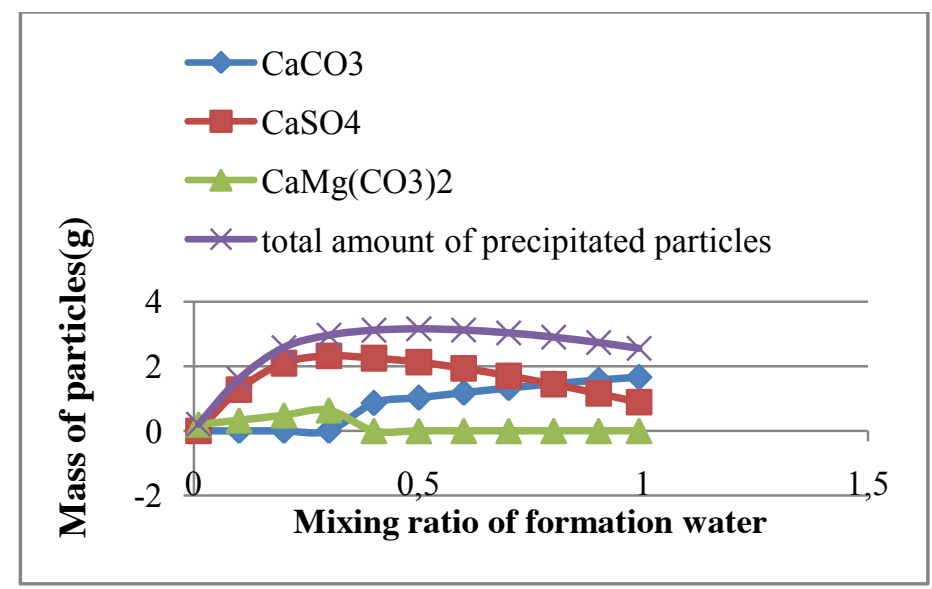

Fig. 1.Determination of scale potential

Moreover, both carbonated and sulfated particles were observed in Figure 1, confirming a complex multi-scale system thatwill be subsequently treated through the utilization of scale inhibitors. It is noteworthy that these results willreliably resemble experimental standard test conditions for a vessel [28].

\subsection{Scale Inhibitor's assessment}

The predicted particle mass and inhibition efficiency are two predominant parameters for studying the green scale inhibitor performance. Scale inhibition efficiency is usually calculated [30] based on the change of calcium ion concentration (Eq. 4) as well as particle mass using Eq. (5) proposed by [31]: 


$$
\begin{aligned}
& \% I=\frac{\left[\mathrm{Ca}^{2+}\right]_{i n}-\left[\mathrm{Ca}^{2+}\right]_{\text {non }- \text { in }}}{\left[\mathrm{Ca}^{2+}\right]_{i}-\left[\mathrm{Ca}^{2+}\right]_{\text {non }- \text { in }}} \times 100 \\
& \% I(\text { Std ave.mean })=\frac{m_{0}-m}{m_{0}} \times 100,
\end{aligned}
$$

where \% $\left[\mathrm{Ca}^{2+}\right]_{i n},\left[\mathrm{Ca}^{2+}\right]_{n o n-i n},\left[\mathrm{Ca}^{2+}\right]_{i}, \mathrm{~m}_{0}$, and $m$ indicate percentages of inhibition, soluble calcium concentration of the inhibited sample, soluble calcium concentration of the non-inhibited sample, initial soluble calcium concentration, mass of noninhibited particles, and mass of inhibited particles, respectively.

Accordingly, Figure 2 shows that increased dosage of the scale inhibitor into the seawater increases the inhibition efficiency until it shows a plateau above $450 \mathrm{mg} / \mathrm{L}$. It can be concluded that $450 \mathrm{mg} / \mathrm{L}$ would be the appropriate dosage for utilization as the optimum dosage of the SI in order to minimize the mass of particles since it is observed in the blue curve. The finding would be justified by the fact that the addition of the SI reduces $\mathrm{pH}$ value due to its acidic functional groups' presence in the SI's chemical structure which may result in less precipitation [32].

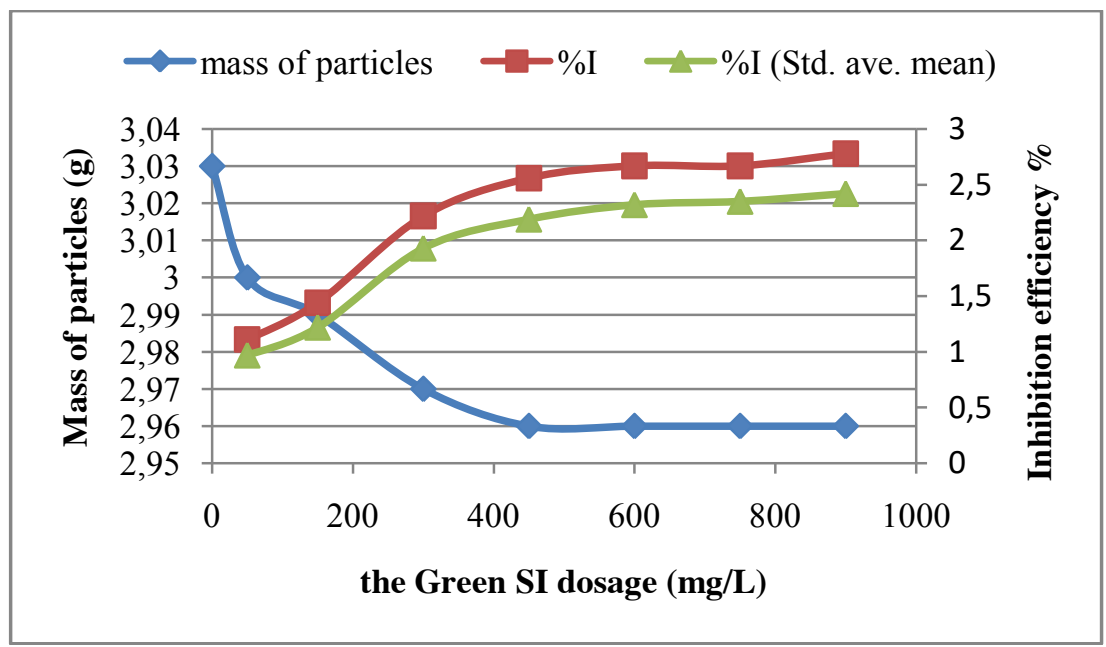

Fig. 2. Mass of particles \& inhibition efficiency vs. dosage of the SI

\subsection{Impact of Rock Presence}

It should be noted that calcite and dolomite rocks are considered in this work due to two reasons: i) carbonated reservoirs account for more than $50 \%$ of the world's hydrocarbon reservoirs [33] most common Iranian scales (calcium carbonate and calcium sulfate) generally result from the complexsurface interactions between brines and carbonated rocks [34]. Consequently, in this part, the brines were exposed to ten grams of calcite and dolomite specifically to assess the SI performance.

According to Fig. 3a, the negative value of the mass of the dolomite particles indicates dissolution phenomena, as expected in the presence of more dolomite in the solid surface, although positive value of the mass ofother particles indicates the precipitation mechanism. Similar findings are observed in Fig. $3 \mathrm{~b}$ relating to dissolution of calcite in the presence of 
calcite rock. One can unambiguously conclude that after coming to equilibrium, the dominant mechanism is precipitation due to the positive "net of particles" bar.



Fig. 3a. Precipitation/dissolution mechanism in the presence of dolomite rock

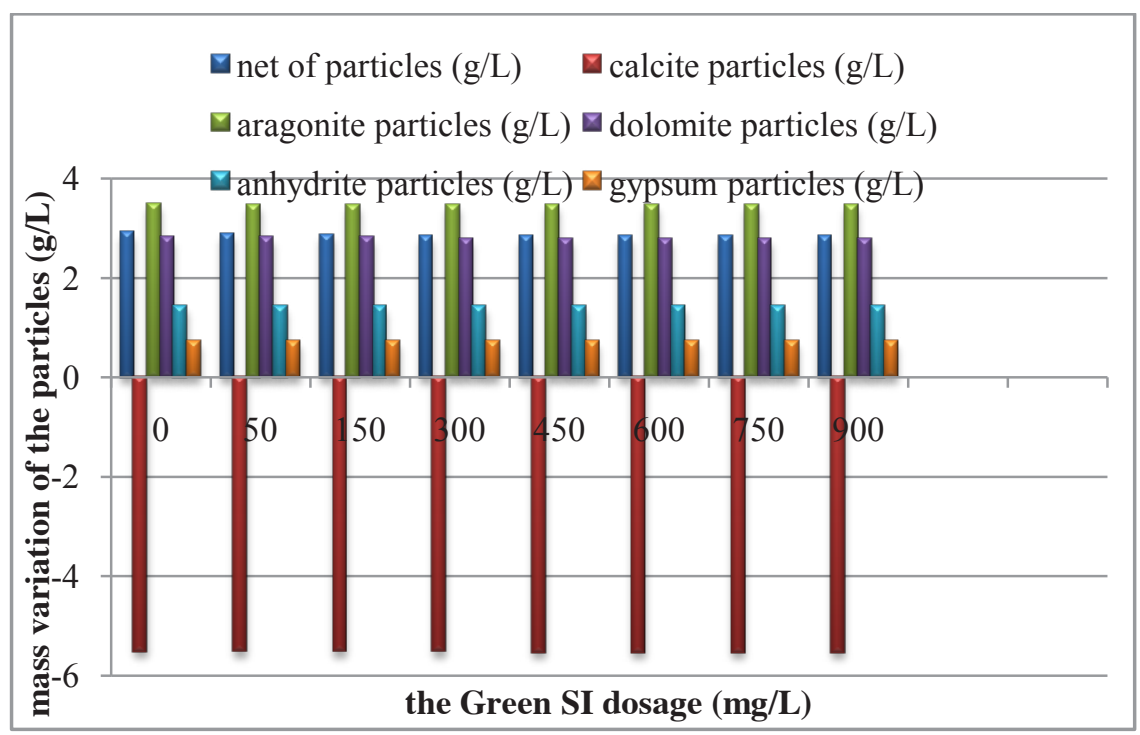

Fig. 3b.Precipitation/dissolution mechanism in the presence of calcite rock

Moreover, Fig. 4 illustrates the impact of two different rocks on the SI performance. More particles will be formed in the presence of the rock due to thedissolution phenomenon of calcium and/or magnesium ions compared to conditions where no rock is present.

Additionally, a comparison of the simulation results between dolomite and calcite shows that because of $\mathrm{Mg}^{2+}$ in dolomite rock, the SI would not be more effective for inhibi- 
tion than calcite rock. In other words, it seems that the dolomite rock interferes with the SI adsorption compared to calcite [36].

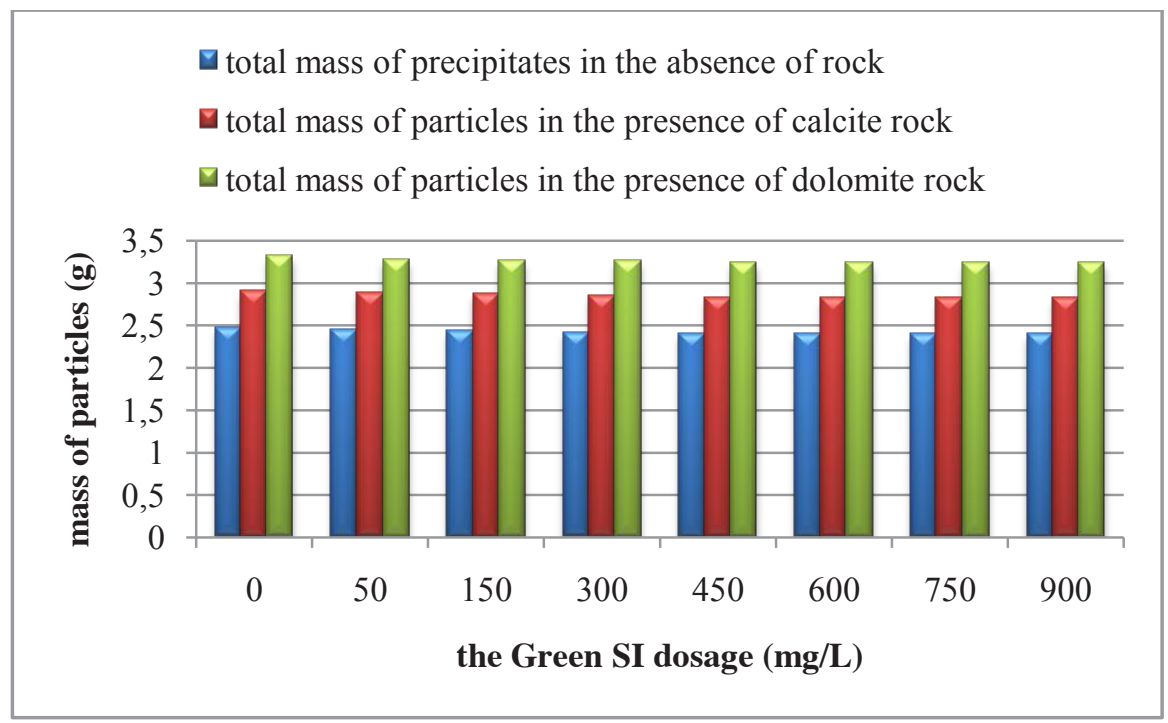

Fig.4. Predicted mass of particles in the absence and presence of the rocks

\section{Conclusions and recommendations}

In this study, the performance of a green scale inhibitor is investigated using an incompatible mixing process and in the presence of rock based on the geochemical PHREEQC model. The main results of this work are as follows:

- The critical mixing ratio of formation and seawater is 50/50 according to the maximum amount of the predicted mass of particles at $90^{\circ} \mathrm{C}$ and atmospheric pressure.

- The optimum SI dose for the defined system is $450 \mathrm{mg} / \mathrm{L}$, because after this dose an asymptotic behavior for inhibition efficiency is observed.

- Although the presence of rock affects SI performance in such a way that more particles are formed compared to the condition of no rock, nonetheless, the adsorption of the SI on calcite is greater than on dolomite. In other words, the SI would be more efficient in the presence of calcite.

- Since PHREEQC is based on equilibrium conditions and reaching equilibrium is not conceivable in reality, experimental tests, as well as characterization analyses such as SEM/EDX are highly recommended to elucidate the SI mechanism. It should be noted that achieving qualitative similar trends between experimental and simulated results would be reasonable and sufficient, consistent with a complex geochemical system in the presence of a chemical like a scale inhibitor.

\section{References}

1. A. A. Olajire A review of oil field scale management technology for oil and gas production, Journal of Petroleum Science and Engineering, 135, 723-737 (2015).

2. T. Zhu, L. Wang, W. Sun, M. Wang, J. Tian, Z. Yang The role of corrosion inhibition in the mitigation of $\mathrm{CaCO}_{3}$ scaling on steel surface, Corrosion Science, 140, 182-195 (2018). 
3. M. Chaussemier, E. Pourmohtasham, D. Gelus, N. Pecoul, H. Perrot, J. Ledion, H. Cheap-charpeneter, O. Horner State of art of natural inhibitors of calcium carbonate scaling . A review article, Deslaniation, 356, 47-55 (2015).

4. H. Guan Scale Deposition Control and Management in Subsea Fields, in NACE International, 1-12 (2015).

5. A. Antony, J. H. Low, S. Gray, A. E. Childress, P. Le-Clech, G. Leslie Scale formation and control in high pressure membrane water treatment systems: A review, Journal of Membrane Science,383, 1-16 (2011).

6. J. Azizi, S. R. Shadizadeh, A. Khaksar Manshad, A. H. Mohammadi A dynamic method for experimental assessment of scale inhibitor efficiency in the oil recovery process by water flooding, Petroleum, 5(3), 303-314 (2019).

7. A. Khormali, D. G. Petrakov Laboratory investigation of a new scale inhibitor for preventing calcium carbonate precipitation in oil reservoirs and production equipment, Petroleum Science, 13(2), 320-327 (2016).

8. J. Zotzmann, A. Vetter, S. Regenspurg Evaluating efficiency and stability of calcite scaling inhibitors at high pressure and high temperature in laboratory scale, Geothermal Energy, 6(18), 1-13 (2018).

9. A. Zeino, M. Albakri, M. Khaled, M. Zarzour Comparative study of the synergistic effect of ATMP and DTPMPA on $\mathrm{CaSO}_{4}$ scale inhibition and evaluation of induction time effect, Journal of Water Process Engineering, 21, 1-8 (2018).

10. H. Zhang, X. Lou, X. Lin, P. Tang, X. Lu, M. Yang, Y. Tang Biodegradable carboxymethyl inulin as a scale inhibitor for calcite crystal growth: Molecular level understanding, Desalination, 381, 1-7 (2016).

11. Q. ZhenHua, C. YongChang, W. XiuRong, S. Cheng, L. YunJie, M. ChongFang Experimental study on scale inhibition performance of a green scale inhibitor polyaspartic acid, Science in China, Series B: Chemistry, 51(7), 695-699 (2008).

12. D. Hasson, H. Shemer, A. Sher State of the art of friendly "green" scale control inhibitors: A review article, Industrial and Engineering Chemistry Research,50(12), 7601-7607 (2011).

13. T. Kumar, S. Vishwanatham, S. S. Kundu A laboratory study on pteroyl-1-glutamic acid as a scale prevention inhibitor of calcium carbonate in an aqueous solution of synthetic produced water, Journal of Petroleum Science and Engineering,71(1-2), 1-7 (2010).

14. A. Martinod, M. Euvrard, A. Fiossy, A. Neville Electrodeposition of a calcareous layer: Effects of green inhibitors, Chemical Engineering Science,64, 2413-2421 (2009).

15. M. Schweinsberg, W. Hater, J. Verdes New Stable Biodegradable Scale Inhibitor Formulations for Cooling Water: Development and Field Tests, 64th International Water Conference, (2003).

16. D. Liu, W. Dong, F. Li, F. Hui, J. Ledion Comparative performance of polyepoxysuccinic acid and polyaspartic acid on scaling inhibition by static and rapid controlled precipitation methods,Desalination, 304, 1-10 (2012).

17. S. Yonghong, X. Wenhua, W. Ying Study on polyepoxysuccinic acid reverse osmosis scale inhibitor, Journal of Environmental Sciences, 21(1), 73-75 (2009).

18. D. L. Verraest, J.A. Peters, H. Bekkum Carboxymethyl Inulin: a new inhibitor for calcium carbonate precipitation, JAOCS, 73(1), 55-62 (1996).

19. S. Kirboga, M. Oner Investigation of calcium carbonate precipitation in the presence of 
carboxymethyl inulin, CrystEngComm, 18, 3678-3686 (2013).

20. S. Kurboga, M. Öner The inhibitory effects of carboxymethyl inulin on the seeded growth of calcium carbonate, Colloids and Surfaces B: Biointerfaces, 91, 18-25 (2012).

21. P. Zhang, Y. Lui, A. T. Kan, M. B. Tomson Laboratory evaluation of the synergistic effect of transition metals with mineral scale inhibitor in controlling halite scale deposition, Journal of Petroleum Science and Engineering, 175, 120-128 (2019).

22. A. M.Abdel-Gaber, B. A.Abd-El-Nabey, E. Khamis, D.E. Abd-El-Khalek Investigation of fig leaf extract as a novel environmentally friendly antiscalant for $\mathrm{CaCO}_{3}$ calcareous deposits, desalination 230, 314-328 (2008).

23. O.Lee,B.Lee, J.Lee, H.Lee, J.Son, C.Park, K.Shetty, Y.Kim Assessment of phenolicsenriched extract and fractions of olive leaves and their antioxidant activities, Bioresource Technology,100(23), 6107-6113 (2009).

24. R.Menzri, S.Ghizellaoui, M.Tlili Calcium carbonate inhibition by green inhibitors: Thiamine and Pyridoxine, Desalination,404, 147-154 (2017).

25. J.Moghadasi, M. Jamialahmadi, H.Muller-Steihagen, A.Sharif, A. Ghalambor, M. R.Izadpanah, E.Motei Scale Formation in Iranian Oil Reservoir and Production Equipment During Water Injection, SPE,(2003).

26. O.Vazquez, P.Herrero,E. Mackey, M.Jordan Non-aqueous vs aqueous overflush scale inhibitor squeeze treatment in an oilfield offshore Norway, Journal of Petroleum Science and Engineering, 138, 1-10 (2016).

27. H.Sharma, K. K. Mohanty An experimental and modeling study to investigate brinerock interactions during low salinity water flooding in carbonates, Journal of Petroleum Science and Engineering,165, 1021-1039 (2018).

28. A. H.Nikoo, L. Mahmoodi, M. R. Malayeri, A. Kalantariasl Gypsum-brine-dolomite interfacial interactions in the presence of scale inhibitor,Chemical Engineering Science,222, 115718 (2020).

29. K.Jarrahian, K. S. Sorbie, M. A.Singleton, L. S.Boak, A.J.Graham The Effect of pH and Mineralogy on the Retention of Polymeric Scale Inhibitors on Carbonate Rocks for Application in Squeeze Treatments, SPE Production \& Operations,34(2), 1-17 (2018).

30. A.Valiakhmetova, K. S.Sorbie, L. S.Boak,S. S. Shaw Solubility and Inhibition Efficiency of Phosphonate Scale Inhibitor-Calcium-Magnesium Complexes for Application in Precipitation,SPE,(2016).

31. A.Khormali, D. G.Petrakov, R.Nazari Moghaddam Study of adsorption/desorption properties of a new scale inhibitor package to prevent calcium carbonate formation during water injection in oil reservoirs, Journal of Petroleum Science and Engineering,153, 257-267 (2017).

32. J. M. M.Ibrahim, K. Sorbie, L. S. BoakCoupled Adsorption / Precipitation Experiments: Non-Equilibrium Sand Pack Treatments,SPE International Conference on Oilfield Scale, (2011).

33. N.Arsalan, S. S.Palayangoda, D. J.Burnett, J. JBuiting, Q. P. Nguyen Surface energy characterization of carbonate rocks,Colloids and Surfaces: Physicochemical and Engineering Aspects,436, 139-147 (2013).

34. J.Moghadasi, H.Muller-Steihagen, M.Jamialahmadi, A.Sharif SCALE DEPOSITS IN POROUS MEDIA AND THEIR REMOVAL BY EDTA INJECTION. 7th Iternational Conference on Heat Exchanger Fouling and Cleaning-Challenges and Opportunities, (2007). 
35. K.Jarrahian, M.Sigleton, L.Boak, K. S. Sorbie Surface Chemistry of Phosphonate Scale Inhibitor Retention Mechanisms in Carbonate Reservoirs, Crystal Growth and Design, 20(8), 5356-5372 (2020). 